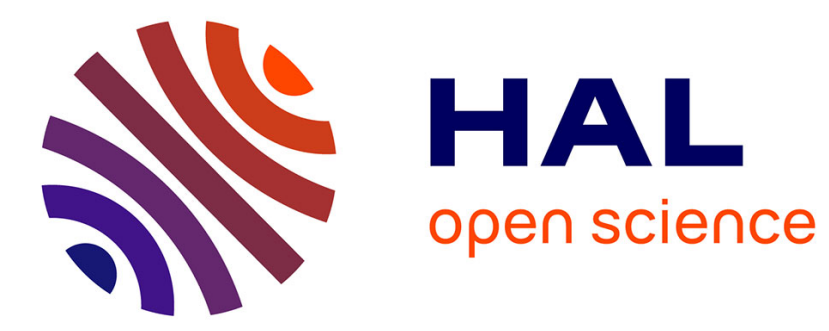

\title{
Characteristic time determination for transport phenomena during the electrokinetic treatment of a porous medium
}

Véronique Pomes, Maria Aurora Fernandez, Didier Houi

\section{- To cite this version:}

Véronique Pomes, Maria Aurora Fernandez, Didier Houi. Characteristic time determination for transport phenomena during the electrokinetic treatment of a porous medium. Chemical Engineering Journal, 2002, 87 (2), p. 251-260. 10.1016/S1385-8947(01)00261-3 . hal-01847603

\section{HAL Id: hal-01847603 \\ https://hal.science/hal-01847603}

Submitted on 7 Nov 2019

HAL is a multi-disciplinary open access archive for the deposit and dissemination of scientific research documents, whether they are published or not. The documents may come from teaching and research institutions in France or abroad, or from public or private research centers.
L'archive ouverte pluridisciplinaire HAL, est destinée au dépôt et à la diffusion de documents scientifiques de niveau recherche, publiés ou non, émanant des établissements d'enseignement et de recherche français ou étrangers, des laboratoires publics ou privés. 


\title{
Characteristic time determination for transport phenomena during the electrokinetic treatment of a porous medium
}

\author{
V. Pomès ${ }^{\mathrm{a}}$, A. Fernández ${ }^{\mathrm{b}, *}$, D. Houi ${ }^{\mathrm{c}}$ \\ a Ecole Nationale Supérieure des Ingénieurs en Arts Chimiques et Technologiques, Institut National Polytechnique de Toulouse, \\ Route de Narbonne, 31000 Toulouse, France \\ ${ }^{\mathrm{b}}$ Centre Energétique Environnement, Ecole des Mines d'Albi-Carmaux, 81013 Albi, France \\ c Institut de Mécanique des Fluides de Toulouse, Avenue Camille Soula, 81400 Toulouse, France
}

\begin{abstract}
Electroremediation is a soil decontamination technique. The electric field applied to a porous medium induces the migration of ionic species in solution. The different phenomena appearing in soil are presented. A new methodological approach is carried out in order to determine if preponderant and/or limiting phenomena can be considered. The theoretical study, using dimensional analysis, showed that transport of ionic species in solution could be described only by electro-osmosis and electromigration phenomena. But, other phenomena, such as heterogeneous reactions, can restrict the migration of ionic species which is only possible for chemical species in solution. Then, an experimental study was carried out with a tracer, in order to verify the theoretical characteristic times for transport phenomena, obtained by dimensional analysis and calculated in a synthetic medium. Rigorous experimental procedures were followed to realise well-controlled electroremediation experiments. The experimental results obtained have allowed the measurement of characteristic times of electrokinetic transport and the theoretical times have been validated. In addition, the application of a simple mass balance equation to the soil and an electrolytic compartment has allowed the verification of the migration behaviour of the mass flux as a front advance.
\end{abstract}

Keywords: Electroremediation; Electrokinetic; Dimensional analysis; Characteristic time; Soil remediation

\section{Introduction}

An electric field applied to a porous medium (such as a soil) induces electrokinetic phenomena in addition to other more classical transport phenomena (such as diffusion or convection) and to chemical reactions. These ones could appear between chemical species in solution (homogeneous reactions) or with the soil (heterogeneous reactions). The electrokinetic phenomena are:

- The electrochemical reactions at the electrodes.

- Electrophoresis, which is the movement of charged particles with respect to a solution. Usually, soils are assimilated with a consolidated porous media so that the transport of solid particles is not considered.

- Electromigration, which is the transport of ions in solution with respect to the solution. The electromigration is considered as a particular case of electrophoresis when the particle size is close to zero [6].

\footnotetext{
* Corresponding author. Tel.: +33-5-63-49-31-45; fax: +33-5-63-49-30-99.

E-mail address: fernande@enstimac.fr (A. Fernández).
}

- Electro-osmosis, which takes place at the solid/liquid interface of the medium [4]. Electro-osmosis induces a displacement of the free water molecules.

For 100 years, electrophoresis and electro-osmosis have been studied and applied in different areas of engineering such as dewatering or chemical analysis [6,7]. A most recent application of these phenomena is the soil depollution in which chemical reactions between the soil and pollutants often make remediation difficult [2,12]. Most authors assume that transport phenomena in soils are very slow and then chemical reactions can be considered in equilibrium [16]. Jacobs and Probstein [10] have showed that characteristic times of the different phenomena can be similar enough to take into account possible chemical limitations for transport species.

However, a phenomenological study of the electroremediation process is complex because of the numerous couplings between the phenomena: couplings can exist between transport phenomena and/or with chemical reactions. In general, transport phenomena and the pollutant reactivity with the medium are separately studied even when their coupling is identified $[3,15]$. 


\begin{tabular}{|c|c|}
\hline \multicolumn{2}{|c|}{ Nomenclature } \\
\hline$c_{i}$ & concentration of species $i(\mathrm{M})$ \\
\hline$c_{i}^{0}$ & initial concentration of species $i(\mathrm{M})$ \\
\hline$c_{\mathrm{IF}}$ & sodium concentration at the inflow (M) \\
\hline$c_{\mathrm{KCl}}$ & potassium chloride concentration (M) \\
\hline$c_{\mathrm{KCl}}^{0}$ & $\begin{array}{l}\text { initial potassium chloride } \\
\text { concentration }(\mathrm{M})\end{array}$ \\
\hline$c_{\mathrm{S}}$ & sodium concentration of the soil $(\mathrm{M})$ \\
\hline$D_{i}$ & $\begin{array}{l}\text { diffusion coefficient of species } i \text { in } \\
\text { free solution at infinite dilution } \\
\left(\mathrm{m}^{2} \mathrm{~s}^{-1}\right)\end{array}$ \\
\hline$D_{i}^{*}$ & $\begin{array}{l}\text { effective diffusion coefficient of } \\
\text { species } i\left(\mathrm{~m}^{2} \mathrm{~s}^{-1}\right)\end{array}$ \\
\hline$F$ & Faraday's constant $\left(96.485 \mathrm{C} \mathrm{mol}^{-1}\right)$ \\
\hline$h$ & hydraulic head $(\mathrm{m})$ \\
\hline$J_{\mathrm{em}}^{\mathrm{Na}}$ & $\begin{array}{l}\text { electromigration mass flux density } \\
\text { of sodium }\left(\mathrm{mol} \mathrm{m}^{-2} \mathrm{~s}^{-1}\right)\end{array}$ \\
\hline$k_{\mathrm{e}}$ & $\begin{array}{l}\text { electro-osmotic coefficient of the } \\
\text { porous medium }\left(\mathrm{m}^{2} \mathrm{~V}^{-1} \mathrm{~s}^{-1}\right)\end{array}$ \\
\hline$k_{\mathrm{h}}$ & $\begin{array}{l}\text { hydraulic conductivity of the } \\
\text { medium }\left(\mathrm{m} \mathrm{s}^{-1}\right)\end{array}$ \\
\hline$\ell$ & distance between the electrodes $(\mathrm{m})$ \\
\hline$L$ & non-dimensional length \\
\hline$N_{\mathrm{eo}}^{\mathrm{Na}}$ & $\begin{array}{l}\text { electro-osmotic mass flux density } \\
\text { of sodium }\left(\mathrm{mol} \mathrm{m}^{-2} \mathrm{~s}^{-1}\right)\end{array}$ \\
\hline$N_{i}$ & $\begin{array}{l}\text { total mass flux density of } \\
\text { species } i\left(\mathrm{~mol} \mathrm{~m}^{-2} \mathrm{~s}^{-1}\right)\end{array}$ \\
\hline$Q$ & flow rate of solution $\left(\mathrm{m}^{3} \mathrm{~s}^{-1}\right)$ \\
\hline$Q_{\mathrm{EK}}$ & electrokinetic flow rate $\left(\mathrm{m}^{3} \mathrm{~s}^{-1}\right)$ \\
\hline$Q_{\mathrm{EM}}$ & $\begin{array}{l}\text { mathematical electromigration } \\
\text { flow rate }\left(\mathrm{m}^{3} \mathrm{~s}^{-1}\right)\end{array}$ \\
\hline$Q_{\mathrm{EO}}$ & electro-osmosis flow rate $\left(\mathrm{m}^{3} \mathrm{~s}^{-1}\right)$ \\
\hline$Q_{\mathrm{IF}}$ & inflow flow rate $\left(\mathrm{m}^{3} \mathrm{~s}^{-1}\right)$ \\
\hline$Q_{\mathrm{OF}}$ & outflow flow rate $\left(\mathrm{m}^{3} \mathrm{~s}^{-1}\right)$ \\
\hline$R$ & universal gas constant $\left(8.3144 \mathrm{~J} \mathrm{~K}^{-1} \mathrm{~mol}^{-1}\right)$ \\
\hline$R_{i}$ & $\begin{array}{l}\text { specific production rate of chemical } \\
\text { species } i \text { due to homogeneous or } \\
\text { heterogeneous chemical reactions } \\
\left(\mathrm{mol} \mathrm{m}^{-3} \mathrm{~s}^{-1}\right)\end{array}$ \\
\hline$S$ & free surface area of the cell \\
\hline$t$ & time $(\mathrm{s})$ \\
\hline$t_{\mathrm{S}}$ & spatial time (s) \\
\hline$T$ & absolute temperature $(\mathrm{K})$ \\
\hline$u_{i}$ & $\begin{array}{l}\text { ionic mobility of species } i \text { in free solution } \\
\text { at infinite dilution }\left(\mathrm{m}^{2} \mathrm{~V}^{-1} \mathrm{~s}^{-1}\right)\end{array}$ \\
\hline$u_{i}^{*}$ & $\begin{array}{l}\text { effective ionic mobility of species } \\
i\left(\mathrm{~m}^{2} \mathrm{~V}^{-1} \mathrm{~s}^{-1}\right)\end{array}$ \\
\hline$V$ & $\begin{array}{l}\text { volume of an electrolytic } \\
\text { compartment }\left(\mathrm{m}^{3}\right)\end{array}$ \\
\hline$x$ & spatial co-ordinate $(\mathrm{m})$ \\
\hline$X_{i}$ & $\begin{array}{l}\text { non-dimensional concentration } \\
\text { of species } i\end{array}$ \\
\hline$z_{i}$ & charge of species $i$ \\
\hline
\end{tabular}

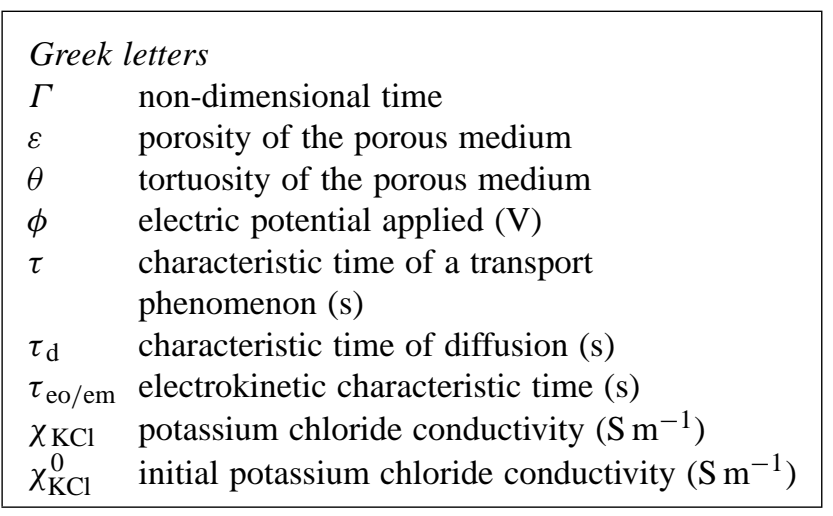

Using a schematic representation of phenomena which can take place during the electroremediation of a soil, transport phenomena and chemical reactions can be considered as series connected groups of parallel circuits characterised by the characteristic times of the different phenomena as showed in Fig. 1.

In a parallel circuit, the lowest resistance (the shortest characteristic time) will correspond with the most important phenomenon. If the characteristic time of a mechanism is smaller than the others, then the corresponding phenomenon will be preponderant. However, in a series resistance circuit, the longest characteristic time (the greatest resistance) will correspond with a limiting phenomenon. If the characteristic time of the chemical reactions is smaller than the characteristic time of the transport phenomena, the influence of the chemical reactions on the transport can then be neglected. If not, transport can be limited by chemical reactions.

The aim of this work is to determine the preponderant and/or limiting phenomena, which appear during the electrokinetic treatment. For this, a dimensional analysis of the mass conservation equation is applied. Characteristic times of transport were theoretically calculated and compared with experimental times of ionic species transport stemming from literature. Then, an experimental study was carried out to validate theoretical characteristic times of transport. Before this, some methodological aspects were carefully studied, characteristic times being very sensitive to the physical and chemical properties of soil. A tracer was used in order to eliminate all possible interactions with the soil.

An in-depth characterisation of the porous medium, procedures of the tracer selection and the experimental set-up are presented. Then, the experimental procedures followed in order to validate the experimental set-up (such as a hydrodynamic study of the electrolytic compartments) and in order to realise a well-controlled electroremediation experiment are explained. Finally, the experimental results obtained are presented and discussed.

\section{Theoretical study}

Transport with chemical reactions for ionic species is described by the mass conservation equation: 


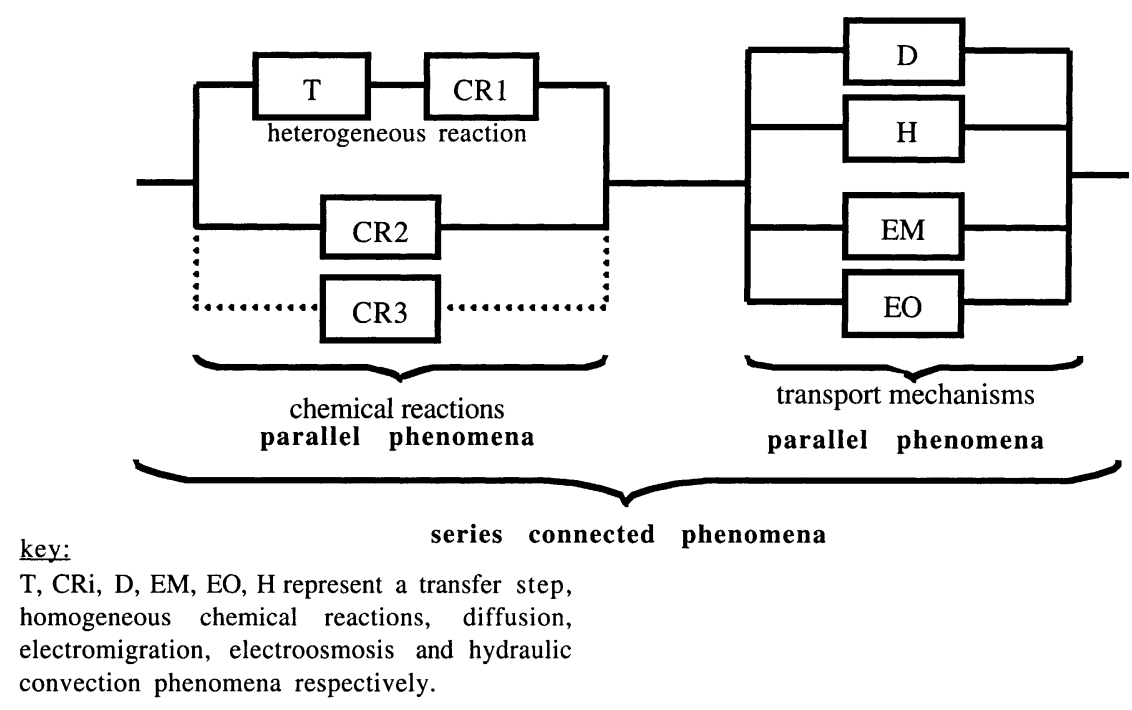

Fig. 1. Representation of electroremediation phenomena by electrical resistances.

$\frac{\partial c_{i}}{\partial t}=-\vec{\nabla} \cdot \vec{N}_{i}+R_{i}$

The following assumptions are often used to describe the species transport under an electric field [5,12]:

- The soil is homogeneous, isotropic and saturated.

- The physical and physicochemical properties of the soil are uniform and constant with time in the steady-state.

- There is no electrophoresis.

- All mass fluxes are linear homogeneous functions of hydraulic, chemical and electrical gradients.

- Isothermal conditions prevail.

- All the applied voltage is effective in fluid and charge transport.

- The electric field is constant with time.

Under the stated assumptions and as electric fields are generally applied between plane electrodes, electroremediation is often studied as a one-dimensional process [5]. Hence, in presence of hydraulic, chemical and electrical gradients, the total mass flux of species $i$ per unit area of the porous medium is described by

$N_{i}=-D_{i}^{*} \frac{\partial c_{i}}{\partial x}-c_{i} u_{i}^{*} \frac{\mathrm{d} \phi}{\mathrm{d} x} \pm c_{i} k_{\mathrm{e}} \frac{\mathrm{d} \phi}{\mathrm{d} x}-c_{i} k_{\mathrm{h}} \frac{\partial h}{\partial x}$

$N_{i}$ being the sum of mass flux densities of diffusion, electromigration, electro-osmosis and convection. Generally, the electro-osmotic flow is from the anode to the cathode. Then, the mathematical expression of the electro-osmotic flow will be $-c_{i} k_{\mathrm{e}}(\mathrm{d} \phi / \mathrm{d} x)$ for a cation and $+c_{i} k_{\mathrm{e}}(\mathrm{d} \phi / \mathrm{d} x)$ for an anion.

The effective coefficient of diffusion and the effective ionic mobility are usually related to the diffusion coefficient, $D_{i}$, and the ionic mobility, $u_{i}$, in free solution at infinite dilution by

$D_{i}^{*}=\frac{\varepsilon}{\theta} D_{i}, \quad u_{i}^{*}=\frac{\varepsilon}{\theta} u_{i}=\frac{D_{i}^{*} z_{i} F}{R T}$
Assuming that the electric potential is constant and the hydraulic potential is negligible during the process, then Eq. (1) becomes

$\frac{\partial c_{i}}{\partial t}=D_{i}^{*} \frac{\partial^{2} c_{i}}{\partial x^{2}}+\nabla \phi u_{i}^{*} \frac{\partial c_{i}}{\partial x} \pm \nabla \phi k_{\mathrm{e}} \frac{\partial c_{i}}{\partial x}+R_{i}$

Acar and Alshawabkeh [1] proposed a dimensional analysis treatment of Eq. (4) to simplify the equations of a predictive numerical model using Damkohler and Peclet numbers.

In the first approximation, this work only considered the transport equations (as for a tracer), the solid/liquid interactions then being neglected $\left(R_{i}=0\right)$.

Eq. (4) becomes

$\frac{1}{\tau} \frac{\partial X_{i}}{\partial \Gamma}=\frac{D_{i}^{*}}{\ell^{2}} \frac{\partial^{2} X_{i}}{\partial L^{2}}+\frac{u_{i}^{*} \nabla \phi}{\ell} \frac{\partial X_{i}}{\partial L} \pm \frac{k_{\mathrm{e}} \nabla \phi}{\ell} \frac{\partial X_{i}}{\partial L}$

where $\Gamma$ is the dimensionless time, $L$ the spatial co-ordinate and $X_{i}$ the concentration are defined using characteristic time $(\tau)$, distance between electrodes $(\ell)$ and initial concentration $\left(c_{i}^{0}\right)$ as reference variables.

The characteristic times of diffusion, $\tau_{\mathrm{d}}$, and of electrokinetic transport, $\tau_{\mathrm{eo} / \mathrm{em}}$, can easily be deduced:

$\tau_{\mathrm{d}}=\frac{\ell^{2}}{D_{i}^{*}}$

and

$\tau_{\mathrm{eo} / \mathrm{em}}=\frac{\ell}{\nabla \phi\left(u_{i}^{*} \pm k_{\mathrm{e}}\right)}$

Practically, mass transport of ionic species by electroosmosis and electromigration cannot be dissociated (electro-osmosis can be neglected only when the soil conductivity is high). A global characteristic time is then defined for both. Table 1 presents theoretical and observed characteristic times obtained for these mechanisms and for various species. 
Table 1

Theoretical and observed characteristic times (electric field: $100 \mathrm{~V} \mathrm{~m}^{-1}$; temperature: $298 \mathrm{~K} ; k_{\mathrm{e}}: 5.0 \times 10^{-9} \mathrm{~m}^{2} \mathrm{~V}^{-1} \mathrm{~s}^{-1} ; \theta: 1.5$ generally used for soil and 1.33 for a kaolinite with a porosity of $0.6[14])$

\begin{tabular}{|c|c|c|c|c|c|c|c|}
\hline Ionic species & Concentration (M) & Porosity & Tortuosity & $\ell(\mathrm{m})$ & $\tau_{\mathrm{d}}$ (days) & $\tau_{\mathrm{eo} / \mathrm{em}}(\mathrm{h})$ & Observed time (h) \\
\hline $\mathrm{OH}^{-}$ & 0.1 & 0.7 & 1.33 & 0.5 & 1188.58 & 15.48 & $480[13]$ \\
\hline $\mathrm{F}^{-}$ & $\infty^{\mathrm{a}}$ & 0.7 & 1.5 & 0.5 & 4203.66 & 63.75 & 445 [9] \\
\hline $\mathrm{Cu}^{2+}$ & $\infty^{\mathrm{a}}$ & 0.6 & 1.33 & 0.1 & 179.66 & 9.24 & $48^{\mathrm{b}}$ \\
\hline $\mathrm{Na}^{+}$ & $\infty^{\mathrm{a}}$ & 0.6 & 1.33 & 0.1 & 192.90 & 9.78 & - \\
\hline
\end{tabular}

a Infinite dilution.

${ }^{\mathrm{b}}$ Low concentration.

Measurement of the electro-osmotic coefficient is not easy. For those theoretical results, a standard value of $k_{\mathrm{e}}$ equal to $5.0 \times 10^{-9} \mathrm{~m}^{2} \mathrm{~V}^{-1} \mathrm{~s}^{-1}$ (for an applied electric field of $100 \mathrm{~V} \mathrm{~m}^{-1}$ ) [7] was used.

The theoretical characteristic times obtained show that electro-osmotic and electromigration seem to be the preponderant transport phenomena. Transport of ionic species in the medium could then be described solely by these mechanisms.

However, the comparison between values of the theoretically estimated and experimentally observed characteristic times shows that they are quite different. That seems to indicate that other phenomena, such as physicochemical interactions between the soil and the pore solution, for example, can restrict the migration of ionic species, which is only possible for chemical species in solution.

Three possibilities can be considered:

1. A retardation effect due to homogeneous or heterogeneous chemical reactions fast enough to consider local equilibrium,

2. A real limitation from a slow heterogeneous chemical reaction, as for example, when a previous transfer step has a limiting effect,

3. For a highly heterogeneous porous medium, a limiting previous step of species diffusion before its electrokinetic recovery.

\section{Experimental work}

\subsection{Porous medium}

The porous medium used for the study was kaolinite clay. In order to constitute a synthetic medium, a well-known mass of kaolinite was saturated under vacuum conditions with a well-known volume of a tracer solution. The solid/liquid ratio was chosen to achieve a final porosity of 0.6 . An in-depth physicochemical characterisation has been made for both the kaolinite powder and the porous medium. Tables 2 and 3 summarise the most important results of these characterisations.

The permeability of the porous medium was measured by Blaine's permeabilimeter [8] and the thermal conductivity by the hot band method [11]. Rahli [14] has shown that a
Table 2

Characteristics of the kaolinite powder

\begin{tabular}{ll}
\hline Particle size distribution (surface distribution & $10 \%: \leq 0.73 \mu \mathrm{m}$ \\
$\quad$ measured by laser diffraction) & $50 \%: \leq 2.61 \mu \mathrm{m}$ \\
& $90 \%: \leq 9.11 \mu \mathrm{m}$ \\
& 2.7 \\
Dry density $\left(\mathrm{g} \mathrm{cm}^{-3}\right)$ & 2.55 \\
$\mathrm{CEC}(\text { meq per } 100 \mathrm{~g})^{\mathrm{a}}$ & 15.4 \\
Specific surface $(\mathrm{BET})\left(\mathrm{m}^{2} \mathrm{~g}^{-1}\right)$ & \\
\hline
\end{tabular}

${ }^{\mathrm{a}}$ Cationic exchange capacity (AFNOR X31-130).

tortuosity equal to 1.33 is suitable at a porosity of 0.6 to a medium where the particles have a length much larger than their diameter, as is the case for kaolinite particles.

Under these conditions, kaolinite is a medium of low permeability with a low exchange capacity. For this system, electroremediation can be more efficient than other remediation processes and interactions between the soil and the pore solution could be simplified.

\subsection{Tracer determination}

In order to choose a tracer to measure characteristic times of transport phenomena, a study was carried out on several ionic species to determine their reactivity with the kaolinite. If any interaction is established, the ionic species is considered (for conditions of $\mathrm{pH}$ and ionic strength of the study) as a tracer. Different ionic species have been tested as tracers for kaolinite in continuous or batch experiments.

Batch experiments have been carried out in order to determine if sodium can be considered as a kaolinite tracer at a $\mathrm{pH}$ value between 5 and 6 . Table 4 presents some results obtained for these experiments for sodium concentrations from 0.01 to $0.1 \mathrm{M}$ in sulphate or chloride solutions. Batch experiments were carried out in two steps. Firstly, the kaolinite was mixed with a sodium solution at $0.01 \mathrm{M}$

Table 3

Characteristics of the porous medium

\begin{tabular}{ll}
\hline Specific surface (Blaine) $\left(\mathrm{m}^{2} \mathrm{~g}^{-1}\right)$ & 1.39 \\
Porosity & 0.6 \\
Tortuosity [14] & 1.33 \\
Permeability $\left(\mathrm{m}^{2}\right)$ & $1.96 \times 10^{-14}$ \\
Thermal conductivity (in the cell) $\left(\mathrm{W} \mathrm{m}^{-1} \mathrm{~K}^{-1}\right)$ & 1.0083
\end{tabular}


Table 4

Sodium reactivity in kaolinite

\begin{tabular}{clcll}
\hline Sample & $\begin{array}{l}\text { Mass of } \\
\text { kaolinite }(\mathrm{g})\end{array}$ & $\begin{array}{l}\text { Time of } \\
\text { contact }(\mathrm{h})\end{array}$ & $\mathrm{pH}$ & $\begin{array}{l}\text { Sodium } \\
\text { concentration } \\
(\mathrm{M})\end{array}$ \\
\hline $\begin{array}{c}\text { Batch experiments in } \\
0\end{array}$ & - & $-01 \mathrm{M}$ chloride solution & & \\
0 & 1.4968 & 2.24 & 5.51 & $1.03 \times 10^{-2}$ \\
1 & 1.5608 & 4.14 & 5.45 & $1.01 \times 10^{-2}$ \\
2 & 1.5119 & 5.08 & 5.60 & $1.00 \times 10^{-2}$ \\
3 & 1.5217 & 24.45 & 5.51 & $1.01 \times 10^{-2}$ \\
4 & & 5.48 & $1.01 \times 10^{-2}$ \\
Experiments in $0.1 \mathrm{M}$ sulphate & solution & & \\
0 & - & - & 5.56 & 0.103 \\
1 & 1.5029 & 1.00 & 5.16 & 0.996 \\
2 & 1.4953 & 2.07 & 5.09 & 0.980 \\
3 & 1.503 & 5.82 & 5.24 & 0.976 \\
4 & 1.5178 & 61.57 & 5.11 & 0.966 \\
\hline
\end{tabular}

concentration, centrifuged and analysed. In the second step, the same samples of kaolinite were mixed with a sodium solution at $0.1 \mathrm{M}$ concentration, centrifuged and analysed. The solid/liquid ratio was constant and equal to $1.5 \mathrm{~g}$ of kaolinite $/ 40 \mathrm{ml}$ of solution. The sodium concentration was measured by atomic absorption at $330.2 \mathrm{~nm}$. The analyses of sodium were made after an equilibrium was reached between the kaolinite and the solution.

The chemical composition of the kaolinite remained constant during the batch experiments. That was verified by the analysis of silicon and aluminium (main elements in the kaolinite) possibly present in the solution after reaching equilibrium. From these results, we have concluded that sodium can be assimilated to a tracer with respect to the kaolinite for a $\mathrm{pH}$ value between 5 and 6 , and for a sodium concentration range between 0.01 and $0.1 \mathrm{M}$.

\subsection{Experimental set-up}

In order to estimate the characteristic times of transport phenomena experimentally, an electroremediation cell was set-up. Fig. 2(a) shows a diagram representing a crosssection of the cell. The both identical electrolytic compartments are easily separable from the cylinder containing the porous medium which length can be modified. Porous medium is put into the cell following a rigorous protocol to guarantee the control of physical properties of the system such as the porosity, permeability and saturation degree. This protocol has been validate by X-ray tomography analyses. Fig. 2 represents the global experimental set-up of the situation of the electroremediation cell.

The cell is placed horizontally in order to avoid hydraulic gradients. A constant electric potential was applied to the electroremediation cell, the current intensity and the electric potential between the electrodes, during the experiment, were measured by two multimeters. Electrolytic solutions are pumped to control the $\mathrm{pH}$, feed concentrations and electrochemical reactions. An external circulation system, with a fast flow pumping rate, guarantees a good mixing in the compartments but not a correct evacuation of the electrolytic gases formed.

A hydrodynamic study previously carried out, allowed us to consider the electrolytic compartments as perfect mixings when electrochemical reactions do not produce gases. For this study, an electrolytic compartment was isolated in the cell and filled with a solution of potassium chloride (initial conductivity: $104.4 \times 10^{-3} \mathrm{~S} \mathrm{~m}^{-1}$ ) and at a precise moment, water (initial conductivity: $246 \times 10^{-6} \mathrm{~S} \mathrm{~m}^{-1}$ ) was suddenly introduced. The conductivity of the solution at the overflow of the compartment was measured continuously, the initial time of measurement corresponding to the introduction of water.

Under the assumption of perfect mixing, the mass balance equation of potassium chloride after the injection of the water can be written as (Eq. (8)) [18]

$V \frac{\mathrm{d} c_{\mathrm{KCl}}}{\mathrm{d} t}=-Q c_{\mathrm{KCl}}(t)$

where $V$ is the volume of the compartment, $Q$ the flow rate of solution of the recirculating pump and $c_{\mathrm{KCl}}$ the potassium chloride concentration into the compartment and at the overflow. Integration of Eq. (8) versus time gives

$\frac{c_{\mathrm{KCl}}(t)}{c_{\mathrm{KCl}}^{0}}=\exp \left(-\frac{t}{t_{\mathrm{s}}}\right)$

where $c_{\mathrm{KCl}}^{0}$ is the initial concentration and $t_{\mathrm{s}}$ the spatial time of the compartment $\left(t_{\mathrm{s}}=V / Q\right)$. The solution conductivity being proportional to the solution concentration, and Eq. (9) can be written as

$\frac{\chi_{\mathrm{KCl}}(t)}{\chi_{\mathrm{KCl}}^{0}}=\exp \left(-\frac{t}{t_{\mathrm{S}}}\right)$

where $\chi_{\mathrm{KCl}}^{0}$ is the initial conductivity and $\chi_{\mathrm{KCl}}$ the conductivity into the compartment and at its outflow. Fig. 3 shows the very good agreement between the experimental and the theoretical results, expressed as dimensionless conductivity.

If gases are produced at the electrodes, a degassing system must be added to allow their correct evacuation, and the system becomes more complex to analyse. So, during experiments, gas formation was avoided as far as possible.

\subsection{Experimental procedures}

For each experiment, kaolinite was saturated with a well-known concentration solution of sodium sulphate $\left(\mathrm{Na}_{2} \mathrm{SO}_{4}\right)$. This concentration is considered as the initial concentration of sodium (tracer) in soil.

Electrolysis of water at the electrodes induces important modifications of the $\mathrm{pH}$ and gas production. At the cathode, that can be avoided by continuously introducing a solution of ammoniumperoxodisulphate $\left(\left(\mathrm{NH}_{4}\right)_{2} \mathrm{~S}_{2} \mathrm{O}_{8}\right)$ which is easier to reduce than water [17]:

$\mathrm{S}_{2} \mathrm{O}_{8}{ }^{2-}+2 \mathrm{e}^{-} \leftrightarrow 2 \mathrm{SO}_{4}{ }^{2-}, \quad E^{0}=2.01 \mathrm{~V}$ 

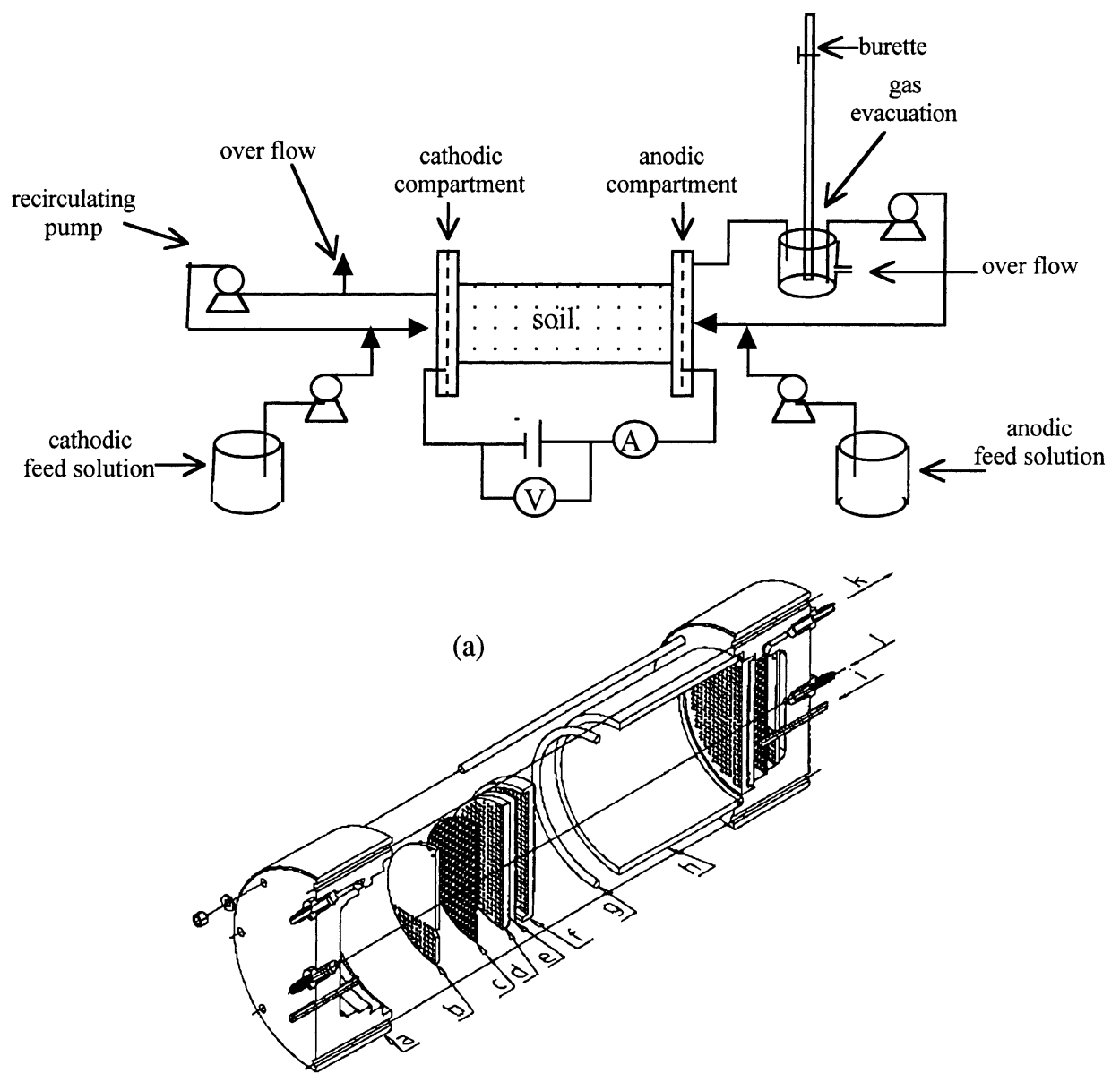

key:

a: Cell

b: Grid to distribute the inflow

g: joint

c: electrode

e: filter

Tube containing the soil

d, Grids to keep the filter in position

i: electrical current

j: inflow

$\mathrm{k}$ : outflow

Fig. 2. Experimental equipment. (a) Details of the electroremediation cell.

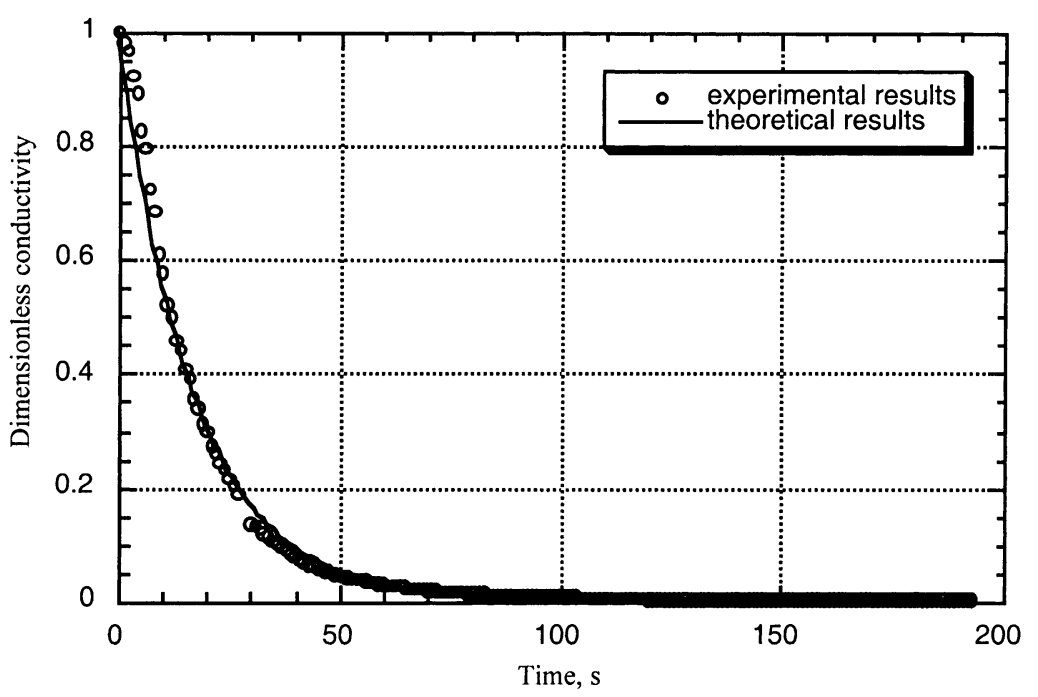

Fig. 3. Hydrodynamic study of the electrolytic compartment. 
$2 \mathrm{H}^{+}+2 \mathrm{e}^{-} \leftrightarrow \mathrm{H}_{2}, \quad E^{0}=0.00 \mathrm{~V}$

The $\mathrm{pH}$ of $\left(\mathrm{NH}_{4}\right)_{2} \mathrm{~S}_{2} \mathrm{O}_{8}$ solution was initially adjusted to a value near to 5-6 (with a potassium hydroxide solution), which is the initial $\mathrm{pH}$ of soil. Reduction of $\mathrm{S}_{2} \mathrm{O}_{8}{ }^{2-}$ ions does not produce gas, and so the cathodic compartment can be easily assimilated to a perfect mixing. Ammonium and potassium ions cannot migrate through the kaolinite because of their positive charge. It was proved that the $\mathrm{S}_{2} \mathrm{O}_{8}{ }^{2-}$ and the $\mathrm{SO}_{4}{ }^{2-}$ ions migration did not modify the soil structure.

At the anode, electrolysis of water and gas formation cannot be avoided. Then, the gas evacuation system was necessary. Nevertheless, the $\mathrm{pH}$ can be controlled by introducing a basic solution. In fact, electrolysis of water depends on the $\mathrm{pH}$ of the solution:

$$
\begin{aligned}
& 4 \mathrm{OH}^{-} \leftrightarrow 2 \mathrm{H}_{2} \mathrm{O}+4 \mathrm{e}^{-}+\mathrm{O}_{2}, \\
& E^{0}=0.401 \mathrm{~V}, \quad \mathrm{pH}>7 \\
& 2 \mathrm{H}_{2} \mathrm{O} \leftrightarrow 4 \mathrm{H}^{+}+4 \mathrm{e}^{-}+\mathrm{O}_{2}, \\
& E^{0}=1.229 \mathrm{~V}, \quad \mathrm{pH} \leq 7
\end{aligned}
$$

If the $\mathrm{pH}$ of the solution at the anode is higher than 7 , electrolysis of water does not produce $\mathrm{H}^{+}$ions which would have to migrate through the soil modifying its $\mathrm{pH}$. The basic feed solution at the anode was sodium hydroxide in order to avoid the introduction of other cations into the system. However, excess hydroxide ions at the anode cannot migrate through the soil because of their negative charge.

The concentration of these electrolyte solutions was high enough to maintain a good conductivity in the compartments, necessary to guaranty that the electric potential gradient applied between the electrodes was effective to the soil. Electrolytic compartments are filled with corresponding solutions at the beginning of the experiments. During experiments, the sodium concentration was measured at the overflow of the cathodic compartment.

\subsection{Results and discussion}

\subsubsection{Convective transport}

In order to verify if convection due to hydraulic gradient can really be neglected, an experiment with the experimental method described above but without the electric field was carried out for a duration of $7 \mathrm{~h}$. Flow rates of the feed solutions were $1.68 \times 10^{-8} \mathrm{~m}^{3} \mathrm{~s}^{-1}$ at the anode and $4.60 \times$ $10^{-8} \mathrm{~m}^{3} \mathrm{~s}^{-1}$ at the cathode. Fig. 4(a) and (b) shows the evolution of sodium concentrations at the cathode and in the soil, respectively.

After $7 \mathrm{~h}$ of experiment, the sodium concentration in the soil had not changed significantly. A slight profile seems to form, probably due to local pressure gradients near the filters. During the experiment, after a previous step of elimination of the residual sodium concentration initially present in the cathodic compartment, the sodium concentration
Table 5

Operating conditions of electrokinetic experiments

\begin{tabular}{lll}
\hline & Experiment A & Experiment B \\
\hline $\begin{array}{l}\text { Electric potential gradient } \\
\left(\mathrm{V} \mathrm{m}^{-1}\right)\end{array}$ & 100 & 100 \\
$\quad$ Length of the soil (m) & 0.1 & 0.1 \\
$\begin{array}{l}\text { Porosity } \\
\text { Tortuosity [14] }\end{array}$ & 0.6 & 0.6 \\
$\quad 1.33$ & 1.33 \\
Sodium concentration in soil (M) & $1.1 \times 10^{-2}$ & $5.065 \times 10^{-2}$ \\
$\quad$ Sodium concentration & 0 & 0 \\
$\quad$ at the cathode $(\mathrm{M})$ & $1.01 \times 10^{-1}$ & $1.01 \times 10^{-1}$ \\
Sodium concentration & & \\
$\quad$ at the anode $(\mathrm{M})$ & $5.64 \times 10^{-8}$ & $5.54 \times 10^{-8}$ \\
Flow rate at the cathode $\left(\mathrm{m}^{3} \mathrm{~s}^{-1}\right)$ & $1.92 \times 10^{-8}$ & $5.27 \times 10^{-8}$ \\
\hline Flow rate at the anode $\left(\mathrm{m}^{3} \mathrm{~s}^{-1}\right)$ & & \\
\hline
\end{tabular}

remained constant at a value close to the residual sodium concentration in the water. These results prove that the porous medium, under working conditions, can be considered impermeable enough to neglect convective transport.

\subsubsection{Electrokinetic transport}

Two electroremediation experiments were carried out in the same conditions with different initial sodium concentrations in soil. Table 5 summarises the operating conditions chosen.

Fig. 5 represents the evolution with time of the sodium concentration measured at the overflow of the cathodic compartment for both experiments A and B. Fig. 5(a) and (b) shows similar behaviour of the evolution of the sodium concentration during the two experiments. Three distinct steps can be observed on these curves. Firstly, the sodium concentration at the cathode quickly increased. Next, the sodium concentration measured remained constant. Finally, the sodium concentration increased regularly. The interpretation of these results can be made taking the characteristic time of electrokinetic transport as a reference.

For $t<\tau_{\mathrm{eo} / \mathrm{em}}$. A constant electrokinetic mass flow of sodium arrives at the cathode from the soil. The first step of the curves represent the non-steady-state mixing in the compartment. During the second step, the sodium concentration remains constant because the mixing has attained the steady-state. Usually, this step will correspond to the remediation of the soil.

For $t>\tau_{\mathrm{eo} / \mathrm{em}}$. Sodium continuously introduced at the anode has migrated through the soil at a different concentration than the initial one. A new non-steady-state mixing at the cathode is established and the sodium concentration at the cathode again increased. This step appears only because of the sodium introduction at the anode to control the conductivity and $\mathrm{pH}$ (it does not take place in a usual depollution operation). This seems to indicate that characteristic times of electrokinetic transport can be experimentally measured. Experimental values of characteristic times of electrokinetic transport for sodium in kaolinite are close to 7.5 and $13 \mathrm{~h}$ for experiments $\mathrm{A}$ and $\mathrm{B}$, respectively. The theoretical 

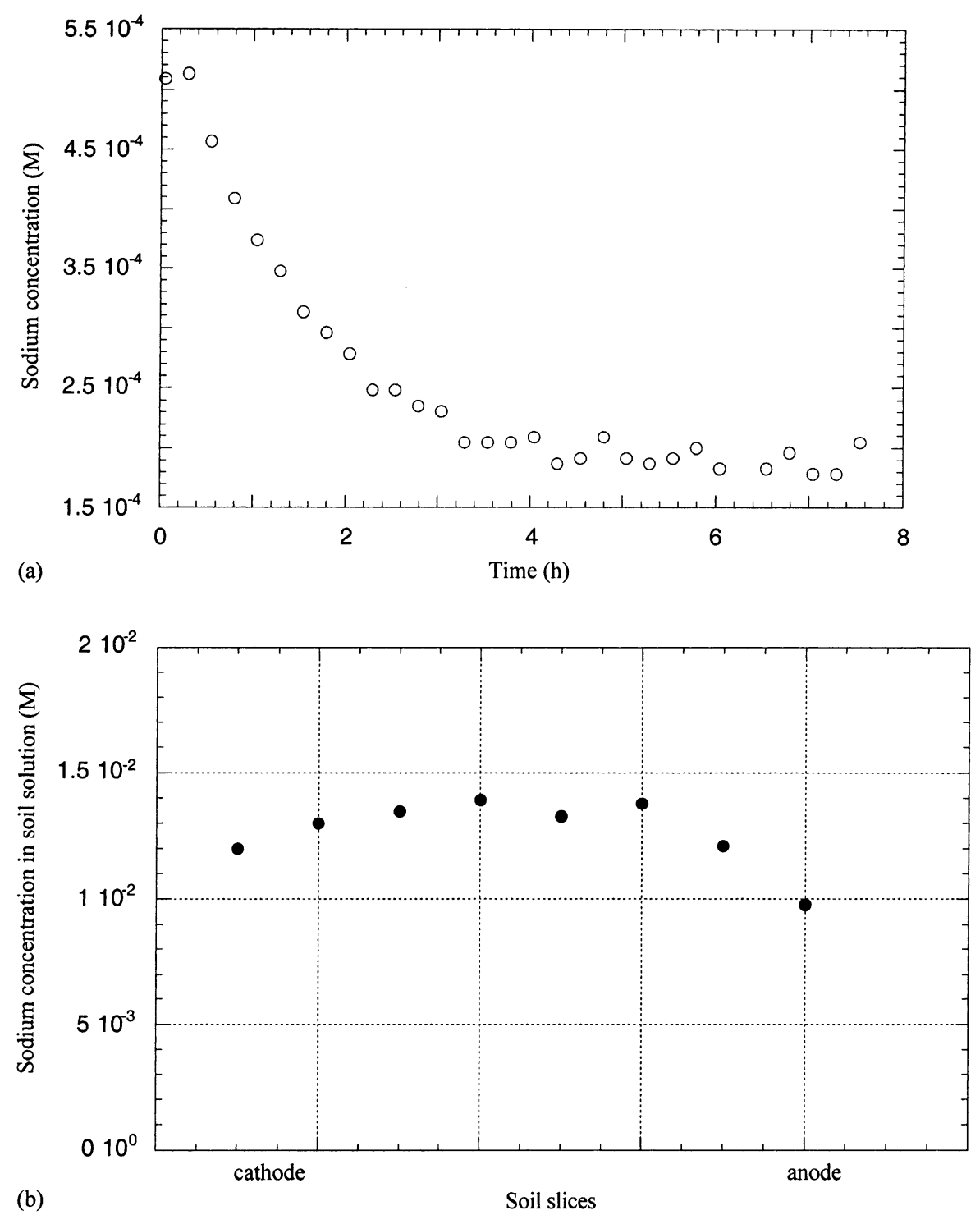

Fig. 4. Experiment without electric field: verification of the convective transport absence in soil. (a) Evolution of the sodium concentration at the cathode with time. (b) Sodium concentration into the soil after $7 \mathrm{~h}$ of experiment.

characteristic time obtained by Eq. (7) is $9.78 \mathrm{~h}$ for the two experiments. There is quite good agreement between the theoretical and experimental values because characteristic times are very sensitive to tortuosity, porosity and electric potential gradient values. The tortuosity used for the calculation was a value taken from the literature [14] and was not experimentally measured. For example, when the tortuosity changes from 1.33 to 1.5 the characteristic time changes from 9.78 to $10.78 \mathrm{~h}$. In addition, the electro-osmotic coefficient, $k_{\mathrm{e}}$, used in the theoretical expression (7) of characteristic time is same for both the experiments. However, the highest sodium concentration in soil (so the highest ionic conductivity) of experiment B should induce an electro-osmotic flux smaller than for experiment $\mathrm{A}$. Then, at higher concentration, the mass flux will be slighter and the characteristic time will be higher.

In order to verify if the electrokinetic transport correspond to a constant mass flux, a simple mass balance equation was applied to sodium at the cathode for $t<\tau_{\mathrm{eo} / \mathrm{em}}$. Fig. 6 describes the system studied.

The mass flux of sodium through the soil by electroosmosis [7] is

$N_{\mathrm{eo}}^{\mathrm{Na}} S=k_{\mathrm{e}} \nabla \phi c_{\mathrm{s}} S=Q_{\mathrm{eo}} c_{\mathrm{S}} \quad$ with $\quad Q_{\mathrm{eo}}=k_{\mathrm{e}} \nabla \phi S$

For the electromigration mass flux, a similar mathematical formulation can be used even when the physical nature of phenomena is different (diffusive transport):

$J_{\mathrm{em}}^{\mathrm{Na}} S=u_{\mathrm{Na}}^{*} \nabla \phi c_{\mathrm{s}} S=Q_{\mathrm{em}} c_{\mathrm{s}} \quad$ with $\quad Q_{\mathrm{em}}=u_{\mathrm{Na}}^{*} \nabla \phi S(16)$

where $Q_{\mathrm{em}}$ here represents only a mathematical not a real flow rate.

The mass balance equation (Eq. (17)) for sodium at the cathode is written as

$Q_{\mathrm{IF}} c_{\mathrm{IF}}+Q_{\mathrm{EK}} c_{\mathrm{S}}-Q_{\mathrm{OF}} c(t)=V \frac{\mathrm{d} c(t)}{\mathrm{d} t}$ 

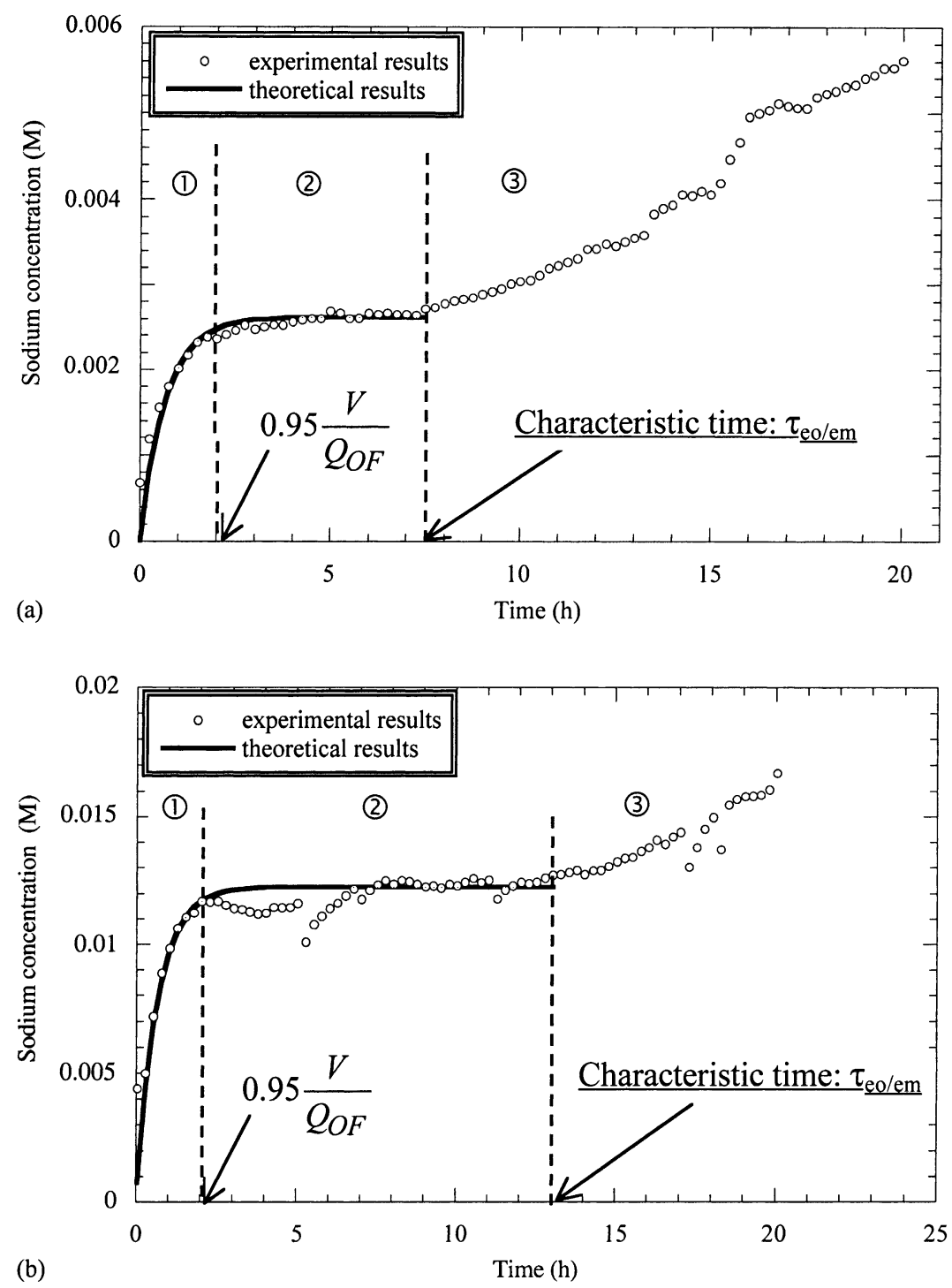

Fig. 5. Evolution with time of sodium concentration at the cathode: $(\bigcirc)$ experimental results; (-) simulation for $t<\tau_{\mathrm{eo} / \mathrm{em}}$. (a) Experiment A; (b) Experiment B.

with

$Q_{\mathrm{EK}}=Q_{\mathrm{eo}}+Q_{\mathrm{em}}$

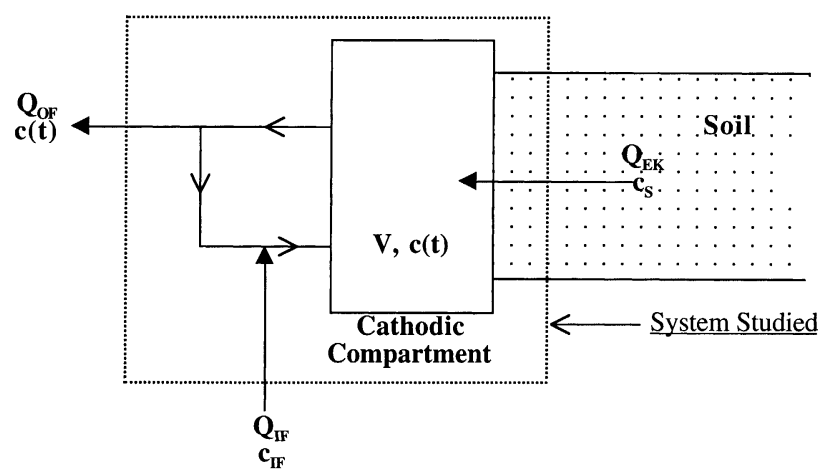

Fig. 6. Cathodic system description for mass balance application. and then

$Q_{\mathrm{EK}}=\left(k_{\mathrm{e}}+u_{\mathrm{Na}^{+}}^{*}\right) \nabla \phi S$

Sodium was not introduced at the cathode with the electrolytic solution, and so the first term of Eq. (17) is equal to zero.

Assuming the electrokinetic mass flux constant (so, the electromigration and the electro-osmotic flows, $Q_{\mathrm{em}}$ and $Q_{\mathrm{eo}}$, are assumed constant and the sodium concentration in soil, $c_{\mathrm{s}}$, is assumed constant and equal to the initial soil concentration), the integration of Eq. (17) versus time for $t<$ $\tau_{\mathrm{eo} / \mathrm{em}}$ gives

$c(t)=\frac{Q_{\mathrm{EK}} c_{\mathrm{s}}}{Q_{\mathrm{OF}}}\left(1-\exp \left(-\frac{Q_{\mathrm{OF}}}{V} t\right)\right)$

Fig. 5 shows the results obtained applying Eq. (19) to ex- 
Table 6

Variables and parameters used for the simulation

\begin{tabular}{lcc}
\hline & Experiment A & Experiment B \\
\hline$k_{\mathrm{e}}\left(\mathrm{m}^{2} \mathrm{~V}^{-1} \mathrm{~s}^{-1}\right)$ & $5 \times 10^{-9}$ & $5 \times 10^{-9}$ \\
$\nabla \phi\left(\mathrm{V} \mathrm{m}^{-1}\right)$ & 100 & 100 \\
$u_{\mathrm{Na}}^{*}\left(\mathrm{~m}^{2} \mathrm{~V}^{-1} \mathrm{~s}^{-1}\right)$ & $2.34 \times 10^{-8}$ & $2.34 \times 10^{-8}$ \\
$\varepsilon$ & 0.6 & 0.6 \\
$S\left(\mathrm{~m}^{2}\right)$ & $4.71 \times 10^{-3}$ & $4.71 \times 10^{-3}$ \\
$Q_{\mathrm{EK}}\left(\mathrm{m}^{3} \mathrm{~s}^{-1}\right)$ & $1.34 \times 10^{-8}$ & $1.34 \times 10^{-8}$ \\
$\mathrm{Q}_{\mathrm{OF}}\left(\mathrm{m}^{3} \mathrm{~s}^{-1}\right)$ & $5.64 \times 10^{-8}$ & $5.54 \times 10^{-8}$ \\
$c_{\mathrm{s}}(\mathrm{M})$ & $1.1 \times 10^{-2}$ & $5.065 \times 10^{-2}$ \\
$V\left(\mathrm{~m}^{3}\right)$ & $1.38 \times 10^{-4}$ & $1.32 \times 10^{-4}$ \\
\hline
\end{tabular}

periments A and B using values of parameters and variables presented in Table 6 .

Fig. 5 shows the very good agreement between experimental results and the theoretical ones obtained by Eq. (19) for $t<\tau_{\mathrm{eo} / \mathrm{em}}$. Thus, we can conclude that under the conditions of experiments $\mathrm{A}$ and $\mathrm{B}$, where sodium concentration in the soil was homogeneous, constant and equal to the initial one, the migration of a tracer through a porous medium by electrokinetic transport can be assumed as a front advances.

\section{Conclusion}

Comparison between observed transport times and theoretical characteristic times of transport mechanisms obtained by dimensional analysis allows to determine if preponderant or limiting phenomena exist. Results obtained for species reacting with kaolinite show that theory and experiments are quite different. It seems to indicate that other phenomena delay the ionic species migration. It can be physicochemical interactions between the soil and the pore solution, for example, in the case of a necessary previous step of species solubilisation during the pollutants recovery. Characteristic times calculated for a tracer in an impermeable medium show that electrokinetic transport phenomena are preponderant over diffusion and they can well represent the system.

The experimental study carried out has allowed the verification of these theoretical characteristic times calculated for a tracer in a synthetic and homogeneous medium, showing that electrokinetic transport is not so slow as usually considered. Then, for well-known physicochemical conditions, an experimental determination of characteristic times of transport is possible. This study has also showed that in order to control fundamental variables of the process, as $\mathrm{pH}$, a perfect mixing in the electrolytic compartments is highly desirable. In all cases, during the experimental works, the measurement of pollutant concentration in electrolytic compartments needs a good knowledge of the hydrodynamic of the experimental set-up.
In addition, for times smaller than the characteristic times, the evolution of the tracer recovery was well represented by a simple mass balance equation just by using a constant electrokinetic mass flux. The good agreement between theoretical and experimental results allowed the validation of the species transport in soil as front advances of the mass flux.

\section{References}

[1] Y.B. Acar, A.N. Alshawabkeh, Modeling conduction phenomena in soils under an electric current, in: Proceedings of the 13th International Conference of Soil Mechanics on Foundation Engineering, Vol. 2, New Delhi, India, 1994, pp. 669-672.

[2] Y.B. Acar, R.J. Gale, G.A. Putman, Acid-base distributions in electrokinetic soil processing, Transport. Res. Rec. A 25 (1990) 687714

[3] Y.B. Acar, J. Hamed, Electrokinetic soil processing in waste remediation and treatment: synthesis of available data, Transport. Res. Rec. 1312 (1991) 153-161.

[4] P. Adler, Electro-osmotic phenomena in porous media, J. Colloid. Interf. Sci. 181 (1996) 169-190.

[5] A.N. Alshawabkeh, Y.B. Acar, Electrokinetic remediation. II Theoretical model, J. Geotech. Eng. 122 (3) (1993) 186-196.

[6] S. Blanco, Mécanisme de séparation des protéines par électrophorèse: modélisation et analyse de sensibilité, Thèse de Doctorat, Université Paul Sabatier, Toulouse, France, 1996.

[7] L. Casagrande, Electro-osmosis in soils, Geotechnique 1 (3) (1949) 159-177.

[8] J. Charpin, B. Rasneur, Caractérisations: mesures des surfaces spécifiques, Techniques de l'Ingénieur P1045 (1982) 1-20.

[9] N. Costarramone, Mise en œuvre au laboratoire et au stade pilote de la décontamination électrocinétique d'un sol dans le cas d'une pollution fluorée, Thèse de Doctorat, Université de Pau et des Pays de l'Adour, France, 1996.

[10] R.A. Jacobs, R.F. Probstein, Two-dimensional modeling of electroremediation, J. AIChE 42 (6) (1996) 2648-2650.

[11] B. Ladevie, Mise au point de dispositifs de caractérisation thermique de matériaux isolants solides ou pâteux: extension aux fluides cisaillés, Thèse de Doctorat, Ecole Nationale Supérieure d'Arts et Métiers, Bordeaux, France, 1998.

[12] J.K. Mitchell, Fundamentals of Soil Behaviour, 2nd Edition, Wiley, New York, 1993, p. 437.

[13] V. Pomès, A. Fernández, D. Houi, Fluorine migration in a soil bed submitted to an electric field: influence of electric potential on fluorine removal, Colloid. Surf. A 159 (1999) 481-490.

[14] O. Rahli, Etude des milieux poreux constitués de fibres rigides: empilements, écoulements et transferts de chaleur, Thèse d'état, Université de Provence-Aix-Marseille I, France, 1997.

[15] J. Salvek, H. Farrah, J. Hamed, Interaction of clays with dilute fluorine solutions, Water, Air Soil Pollut. 23 (1984) 209-220.

[16] A.P. Shapiro, P.C. Renaud, R.F. Probstein, Preliminary studies on the removal of chemical species from saturated porous media by electro-osmosis, Physicochem. Hydrodyn. 11 (5/6) (1989) 785-802.

[17] B. Tremillon, Electrochimie Analytique et Réactions en Solution, Vol. 1, Masson, Paris, 1993.

[18] J. Villermaux, in: Lavoisier (Ed.), Génie de la Réaction Chimique, Conception et Fonctionnement des Réacteurs, 2nd Edition, TEC \& DOC, 1993. 